ZOOLOGIA 30 (1): 15-23, February, 2013

http://dx.doi.org/10.1590/S1984-46702013000100002

\title{
Parental care behavior in the Guiana dolphin, Sotalia guianensis (Cetacea: Delphinidae), in Ilha Grande Bay, southeastern Brazil
}

\author{
Rodrigo H. O. Tardin ${ }^{1,3}$, Mariana A. Espécie' ${ }^{1}$ Liliane Lodi² \& Sheila M. Simão \\ ' Laboratório de Bioacústica e Ecologia de Cetáceos, Departamento de Ciências Ambientais, Instituto de Florestas, Universidade \\ Federal Rural do Rio de Janeiro. Rodovia BR 465, km 7, 23890-000 Seropédica, RJ, Brazil. \\ 2 Projeto Golfinho-Flíper, Instituto Aqualie. Rua Edgard Werneck 428, casa 32, Jacarepaguá, 22763-010 Rio de Janeiro, RJ, Brazil. \\ ${ }^{3}$ Corresponding author: E-mail: rhtardin@gmail.com
}

\begin{abstract}
Parental care is any form of parental behavior that increases offspring fitness. To the authors' knowledge, this study is the first to analyze the intensity of parental care in the Guiana dolphin, Sotalia guianensis (van Bénéden, 1864). The objectives of this study are as follows: 1) to quantify the degree of parental care in S. guianensis in Ilha Grande Bay, Rio de Janeiro; 2) to investigate the influence of behavioral state and group size on the degree of parental care; and 3) to evaluate the differences between the intensity of parental care provided to calves and juveniles. Our results indicate that the intensity of parental care is high in S. guianensis and that care is more intense in larger groups. It is possible that these differences serve to maximize hydrodynamic gains and to minimize risks. Our results suggest that parental care is more intense during travel. A possible reason for this greater intensity is that the feeding dynamics show a more random pattern than other behavioral states. Moreover, the results indicate that calves receive more intense care than juveniles. These results suggest that parent-offspring conflict is possible in the study population.
\end{abstract}

KEY WORDS. Adult-offspring relationship; parent-offspring conflict.

In mammalian societies, the production and care of the young is a fundamental element because useful models of ecology, social behavior and population dynamics can be developed to incorporate the consequences of parental care (WHITEHEAD $\&$ Mann 2000). From this perspective, parental care can be defined as any form of behavior by the parent that appears to enhance the fitness of its offspring (CLUTTON-BRock et al. 2006). Several authors have investigated the amount of time and energy that parents allocate to the care of their offspring (MURRAY et al. 2009), whereas others have evaluated how the residual reproductive and survival values may be diminished by intense parental care (PAREDEs et al. 2005).

In mammals, parental care is associated, in general, with the mother. In this taxon, care is extended beyond gestation. As a result of postgestational parental care, females may lose weight (Millar 1978) and modify their behavior (Szabo \& Duffus 2008). Parental care in mammals is better studied in terrestrial taxa, such as carnivores (e.g., CLuTTON-BRock et al. 2006), but it is poorly understood for marine mammals, especially for species that spend the majority of the time submerged, as is the case for cetaceans.

Cetaceans are long-lived animals and K-strategists. They have extended gestational periods (Whitehead \& MANN 2000), and the offspring are known to have an underdeveloped physiology (NoRen 2007) associated with high levels of mortality (Whitehead \& Mann 2000). Therefore, offspring often tend to stay with the mother for prolonged periods of time, even if they are nutritionally independent (MANN \& SMUTs 1999).

Studies that systematically and quantitatively investigate the mother-offspring relationship in wild cetaceans are scarce. Most of these studies concentrate on accessible species known through long-term research. These species include the North Atlantic right whale, Eubalaena glacialis (P.S.L Müller, 1776) (Hamilton \& Cooper 2010); the humpback whale, Megaptera novaeangliae (Borowski, 1781) (SzABo \& Duffus 2008); the IndoPacific bottlenose dolphin, Tursiops aduncus (Ehrenberg, 1833) (Mann \& Smuts 1999); and the killer whale, Orcinus orca (Linnaeus, 1758). Such studies have focused on infant carrying behavior and the associated infant echelon position (MANN \& SMuTs 1999), which is reported to provide hydrodynamic (Noren 2007) and offspring feeding benefits (MAnN \& SMUTS 1999). Infant carrying behavior is observed in six of 19 orders of eutherian mammals (Ross 2001) and is the second most costly behavior in mammals (Altmann \& SAmuels 1992). This behavior is an evolutionary strategy in species in which the offspring accompany the adults and are subject to environmental challenges after birth (Ross 2001), as is the case for cetaceans. Parental care appears to differ with offspring age and with other characteristics of the offspring. TRIVERs (1974) hypothesized that parent and offspring would have a conflict of interest over the duration of parental care. For example, the care of juveniles would require an increasing amount of time, and the parents 
would benefit if they decreased the intensity of care provided to the juveniles to invest in calves. This conflict would be enhanced as a result of the maturational processes affecting the offspring. Parental care of the calves would be intense, but the care of the juveniles would be less intense because the parent would be interested in investing more energy in future offspring.

Despite substantial effort during recent decades, parental care is poorly understood for the "data deficient" (SECCHI 2010) Guiana dolphin, Sotalia guianensis (van Bénéden, 1864) (e.g., Monteiro-Filho et al. 2008, Rautenberg \& Monteiro-Filho 2008). Sotalia guianensis occurs from central Honduras (CARR \& Bonde 2000) to southern Brazil (SIMÕEs-Lopes 1988) and displays a multi-male mating system with sperm competition but does not exhibit sexual dimorphism (Rosas \& Monteiro-FilHo 2002). The gestational period is estimated to be 12 months, and lactation is estimated to last for 8.7 months. The age of females at sexual maturity may be approximately 5-8 years (Rosas \& Monteiro-FilHo 2002), and calving intervals may range between two and three years (SANTOS et al. 2001).

Recently, the Brazilian National Plan for Small Cetaceans (Rocha-CAmpos et al. 2011) recommended that behavioral aspects of resident populations of $S$. guianensis be investigated for the next five years to help re-evaluate the conservation status of these animals. One objective of this study is to quantify the degree of parental care shown by S. guianensis in Ilha Grande Bay. In this study, we test the hypothesis of parental care and evaluate the prediction that a demonstrable degree of parental care would be observed in this species. This expectation is consistent with previous studies of the common bottlenose dolphin, Tursiops truncatus (Montagu, 1821), which reported that offspring show an underdeveloped physiology (NOREN 2007). The second objective of the study is to investigate how the behavioral state and group size influence the intensity of parental care in groups containing both adults and offspring. The working hypothesis is that the intensity of care will vary according to different behavioral states and in groups of different sizes. The associated prediction is that parental care in groups with larger mean sizes will be stronger because mother-offspring dyads can associate with different individuals and therefore experience increased rates of agonistic behavior, especially from males seeking to copulate. An additional prediction is that parental care will be less intense during feeding behavior because the physical proximity of the offspring can constrain the mothers' ability to herd and capture prey. This hypothesis is derived from data on T. truncatus indicating that mothers reduced their speed of movement up to $76 \%$ compared to mothers without offspring (Noren 2007). The third objective of this study is to evaluate differences in the intensity of parental care furnished to calves and juveniles. Based on the hypothesis and predictions that we aim to test, the intensity of care is expected to vary according to maturational processes. According to this expectation, juveniles would receive less parental care. In this study, we propose a novel method of analyzing parental care. This method involves investigations of behavior that facilitates infant movement and of behavior that protects offspring against agonistic interactions in S. guianensis.

\section{MATERIAL AND METHODS}

Ilha Grande Bay $\left(23^{\circ} 02^{\prime} \mathrm{S}, 44^{\circ} 26^{\prime} \mathrm{W}\right)$ is located along the southern coast of the state of Rio de Janeiro. Together with Sepetiba Bay, it forms an extensive estuarine system (SIGNORINI 1980). The western part of the bay, where boat trips were conducted as part of this study $\left(23^{\circ} 02^{\prime} \mathrm{S}, 44^{\circ} 26^{\prime} \mathrm{W}\right)$, is relatively shallow $(<10 \mathrm{~m})$ (Nogara 2000) and receives organic matter from river drainages and from biomass produced by mangroves (SIGNORINI 1980). This bay receives nutrient-rich sea waters derived from the South Atlantic Central Waters (SACW) (SIGNORINI 1980). The western part is preferentially used by $S$. guianensis (LoDI 2003a) and is surrounded by an outer region ranging in depth between 20 and $40 \mathrm{~m}$ (Nautical chart \#1633,), with a smaller proportion of islands and rocky coasts than the inner region.

This area contains the largest aggregation observed for this species at a single time was found in this area (Lodi \& HetzeL 1998), with individuals exhibiting different degrees of residence in the area (EsPÉcIE et al. 2010).

We conducted seven boat trips per season (about six hours of observation effort per trip) for three years (from May 2007 to March 2010) on board a $7.5 \mathrm{~m}$ vessel equipped with a YAMAHA $^{\circledR} 22$ HP inboard engine. When a group of dolphins was sighted, the boat's velocity was reduced and a $15 \mathrm{~m}$ distance from the group was maintained. Focal-animal sampling procedures were used. The sampling was continuous, and a SONY DCR-TRV $120^{\circledR}$ digital handycam was used to collect data. The use of the digital handycam was desirable for recording adult-offspring relationships because spatial and temporal interactions could be observed in slow motion, increasing the quality of the analysis. This advantage is especially important because the time that dolphins spend at the surface, permitting visual observations, can be very brief.

Our definition of a group followed the SMOLKER et al. (1992) chain rule, in which dolphins separated by a distance of $10 \mathrm{~m}$ or less were considered to be members of the same group. Distance was measured during the analysis of the video clips. The dolphins' body sizes could be used as proxies for distance to determine whether animals belonged to the same group.

As in certain other delphinids (e.g., T. aduncus), S. guianensis displays fission-fusion social dynamics, with group size and members changing in minutes or seconds (e.g., SANTOS \& Rosso 2008). We believe that it was possible to count given groups twice but that the probability of double counting was reduced because of the fission-fusion dynamics and the size of the population.

We used the category of adults throughout this study, but we believe that the adults observed rearing the offspring were parents because the individuals that are affected by the costs associated with this form of behavior are those that have previously invested a substantial amount of energy to benefit 
the offspring, as is the case for parental care in mammals (CLutTon-Brock 1991). Therefore, we assumed that any adult located less than one adult body length from the offspring was the mother. This assumption may have been a source of bias in the data because allomaternal care might be occurring. However, this approach was used because there is no sexual dimorphism in this species (Rosas \& Monteiro-Filho 2002). The only way to effectively determine the sex of an adult is to perform a genetic analysis of the living animal.

To investigate how the size and behavior of the group influenced parental care, we first defined the category of offspring to include both calves and juveniles. Within this category, we defined individuals as calves (individuals $\leqslant 1 / 2$ of adult length) and juveniles (individuals larger than $1 / 2$ and smaller than $2 / 3$ of adult length) (GeIse et al. 1999), to investigate variation in parental care as a function of the developmental stage of the offspring.

The behavioral states used in this study were based on those defined in KARCSZMARSKI et al. (2000): feeding was defined, as an absence of directional movements, accompanied by diving in an asynchronous manner, whereas traveling was defined as the presence of continuous and directional movements.
To investigate if parental care was performed, we developed a new analytical approach. We used two specific categories for analysis; longitudinal and transverse care. Two positions were established for both longitudinal and transverse care.

To characterize longitudinal care, we considered that parental care was evident if an adult positioned itself longitudinally ahead of the offspring. In this study, this position included the infant echelon position commonly described in the cetacean literature (MANN \& SMUTS 1999). This position was defined as longitudinal position 1 (Fig. 1). If the adult did not position itself ahead of the offspring, i.e., if it positioned itself longitudinally behind the offspring, no parental care was assumed. This position was defined as longitudinal position 2 (Fig. 2).

To characterize transverse care, we considered that parental care was evident if an adult positioned itself between the boat and the offspring. The boats considered in this context included any boat located near the dolphins, including the research boat. This position was defined as transverse position 1 (Fig. 3). If the adult did not position itself between the boat and the offspring, i.e., the offspring was located between the boat and the adult, no parental care was assumed. This position was defined as transverse position 2 (Fig. 4). Given
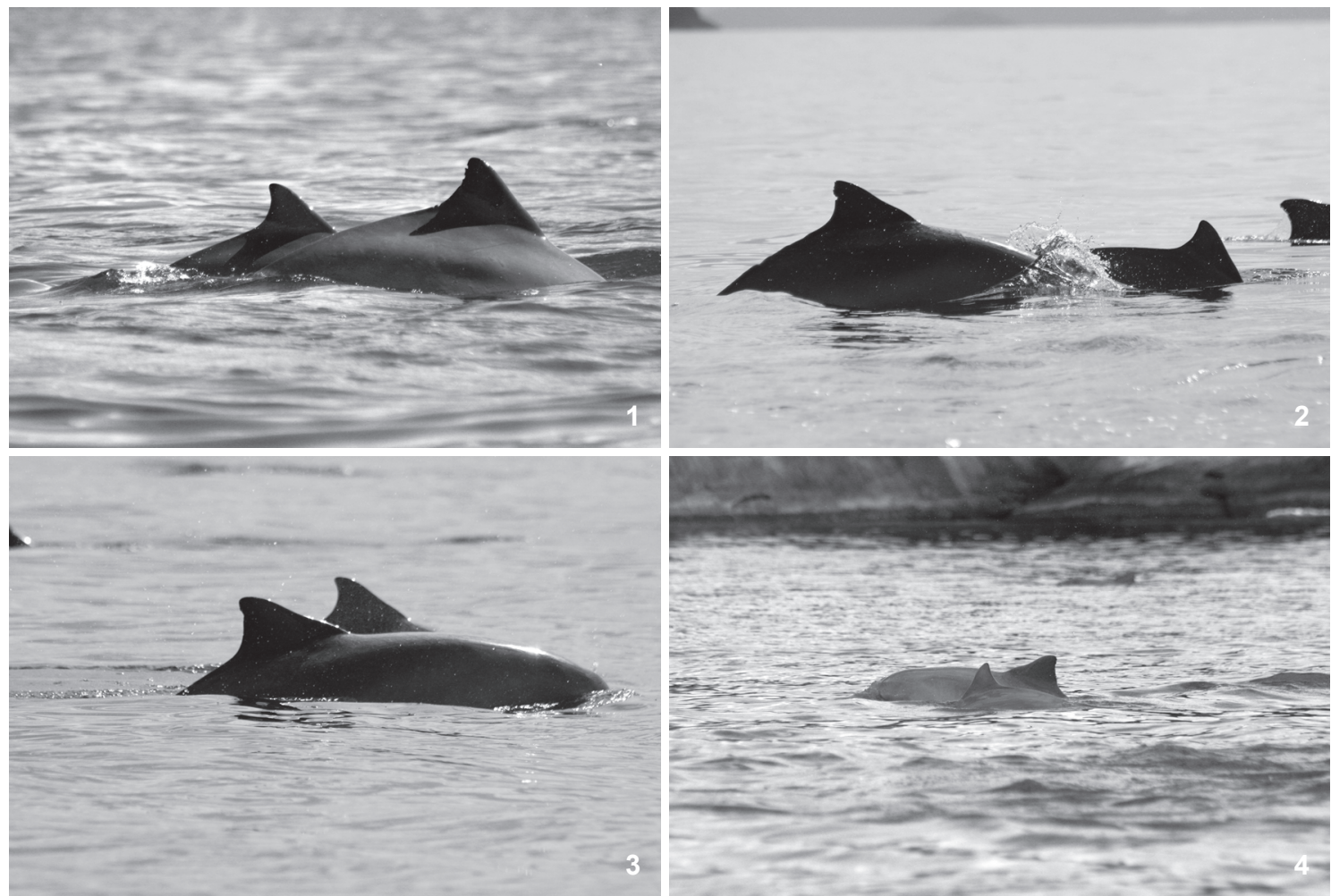

Figures 1-4. Positions of adult-offspring dyad of Sotalia guianensis, in Ilha Grande Bay, Rio de Janeiro: (1) longitudinal position 1, when the adult located itself longitudinally ahead the offspring; (2) longitudinal position 2, when the adult was locating itself longitudinally behind the offspring; (3) transversal position 1 when the adult positioned itself between the boat and the offspring; (4) transversal position 2, when the adult was not positioning itself between the boat and the offspring. Photos by Mariana Espécie. 
these positions for longitudinal and transverse care, we quantified the amount of time that each type of parental behavior was observed. The length of time was chosen as the measure because groups in some situations were observed for prolonged periods (approximately 1-5 minutes), allowing the exact duration of parental care to be quantified.

To evaluate which of the parental care types (longitudinal or transverse) was preferred by adults, we defined four subcategories, measured in seconds:

Total Care (TC): The adult behaved to protect the offspring both longitudinally and transversely (longitudinal and transverse positions 1). Total Longitudinal Care (TLC): The adult behaved to protect its offspring longitudinally but not transversely (longitudinal position 1 and transverse position 2). Total Transversal Care (TTC): The adult behaved to protect the offspring transversely but not longitudinally (transverse position 1 and longitudinal position 2). Absence of Care (AC): The adult did not protect the offspring longitudinally or transversely (longitudinal and transverse positions 2)

We acknowledge that offspring may take an active role by taking protected positions to increase their own benefits. However, we observed that mothers had an active role in most cases. On many occasions, we observed mothers actively providing care both longitudinally and transversely. For instance, this behavior pattern sometimes occurred if a calf was closer to the boat than its mother and an active change in position was initiated by the mother. Moreover, mothers are not subject to the same physiological and muscular constraints that influence the behavior of the offspring. For this reason, the mothers are best capable of changing their position and have the flexibility necessary to position themselves.

To quantify the tendency of the offspring to be protected by the adult both longitudinally and transversely, we used a Mann-Whitney U test. The same test was used to determine whether group sizes influenced the time taken by adults to protect their offspring both longitudinally and transversely.

To determine whether the behavioral state of the group containing the adult and its offspring influenced longitudinal and transverse care, we used a Kruskal-Wallis test. The variables included in this test were as follows: offspring feeding in longitudinal/transverse position 1 (P1F), offspring feeding in longitudinal/transverse position 2 (P2F), offspring traveling in longitudinal/transverse position 1 (P1T) and offspring traveling in longitudinal/transverse position 2 (P2T). The groups were used as the cases for the test. If we discriminated between offspring in two developmental stages (calves and juveniles), we used a Kruskal-Wallis test to determine whether parental care (both longitudinal and transverse) was performed in degrees that differed between these two developmental stages. We used the following variables in this approach: calves in longitudinal/transverse position 1, calves in longitudinal/transverse position 2, juveniles in longitudinal/transverse position 1 and juveniles in longitudinal/transverse position 1 . By quantifying the four sub-categories created, the same test was used to investigate which type of parental care (longitudinal or transverse) was observed more frequently

\section{RESULTS}

We conducted 28 boat trips, which resulted in 100.5 hours of effort and 42.1 hours of direct observation (41.9\%). We observed a total of 1,343 groups, including possible double counts (16.7 \pm 17.9 individuals, range: $2-200$ individuals). Because a total of 1,268 (94.4\%) of these groups included offspring, we could conduct an analysis of parental care.

\section{Longitudinal care}

Adults located themselves ahead of their offspring more often than expected, and calves received care for a longer total time than juveniles (Table I). In longitudinal care, we observed adults locating themselves ahead of their offspring for a total of 160,830 seconds $(86.5 \%$, mean value $57 \pm 64$ s). Adults located themselves behind their offspring for a total of 25,080 seconds ( $13.5 \%$, mean value $43 \pm 54 \mathrm{~s})$. A Mann-Whitney test showed significant differences between the time offspring were in position 1 and in position $2\left(\mathrm{U}=656.5, \mathrm{~N}_{\text {position } 1}=2,933\right.$, $\mathrm{N}_{\text {position } 2}=584, \mathrm{p}=0.000001$ ) (Table I). If we divided offspring into developmental stages, a Kruskal-Wallis test showed significant differences between the length of time adults spent longitudinally protecting calves and juveniles $\left(\mathrm{N}=2,656, \mathrm{H}_{3}=\right.$ 92.1, p = 0.0001) (Table I). A post hoc multiple comparison of means did not find significant differences between juveniles in position 1 and calves in position $2(p=0.5)$ or between juveniles in position 2 and calves in position $2(\mathrm{p}=0.5)$.

The mean group size observed for longitudinal position 1 was $27.5 \pm 30.1$, and that for position 2 was $24.4 \pm 34$. 1 . The size of the groups including both adult and offspring differed significantly relative to the duration of longitudinal care (MannWhitney test, $\mathrm{U}=740.0, \mathrm{~N}_{\text {position } 1}=2,940, \mathrm{~N}_{\text {position } 2}=580, \mathrm{p}=$ 0.000001).

The length of time that the adults located themselves in position 1 and in position 2 differed significantly according to the behavioral state (Kruskal-Wallis test, $\mathrm{N}=2,655, \mathrm{H}_{3}=188.1$, $\mathrm{p}=0.0001$ ) (Table I). A post hoc multiple comparison of means did not find significant differences between offspring traveling in position 2 and offspring feeding in position $1(\mathrm{p}=1.0)$.

\section{Transverse care}

In transverse care, we observed the adults locating themselves between their offspring and the boat more often than expected, and the adults protected calves more often than they protected juveniles (Table I). We observed this position (transverse position 1 ) for a total of 172,446 seconds $(89.1 \%$, mean $60 \mathrm{~s} \pm 67 \mathrm{~s}$ ). We observed offspring between the boat and the adult (transverse position 2) for a total of 21,054 seconds $(10.9 \%$, mean $34 \mathrm{~s} \pm 61 \mathrm{~s})$. A Mann-Whitney test found significant differences between the length of time offspring were in 
Table I. Duration in seconds of each category and position of parental care for calves, and juveniles of Sotalia guianensis and batched as offspring for feeding and travelling behavior in Ilha Grande Bay, Rio de Janeiro.

\begin{tabular}{|c|c|c|c|c|}
\hline \multirow{2}{*}{ Parental care } & \multicolumn{2}{|c|}{ Developmental Stages } & \multicolumn{2}{|c|}{ Offspring } \\
\hline & Calf & Juvenile & Feeding & Travelling \\
\hline Longitudinal position 1 & $60.3 \pm 70.2$ & $44.4 \pm 44.5$ & $47.9 \pm 36.6$ & $79.9 \pm 98.9$ \\
\hline Longitudinal position 2 & $47.3 \pm 64.3$ & $30.5 \pm 24.3$ & $37.3 \pm 30.1$ & $57.4 \pm 80.3$ \\
\hline Transversal position 1 & $62.4 \pm 75.1$ & $45.3 \pm 44.5$ & $49.2 \pm 37.4$ & $81.9 \pm 102.2$ \\
\hline Transversal position 2 & $34.5 \pm 27.2$ & $27.1 \pm 17.6$ & $31.7 \pm 22.5$ & $36.9 \pm 29.5$ \\
\hline
\end{tabular}

position 1 and $2\left(\mathrm{U}=710.0, \mathrm{~N}_{\text {position } 1}=2,895, \mathrm{~N}_{\text {position } 2}=619, \mathrm{p}\right.$ $=0.0000001$ ) (Table I). If we divided the offspring into developmental stages, a Kruskal-Wallis test showed significant differences between the length of time adults transversely protected calves and juveniles $\left(\mathrm{N}=2,656 ; \mathrm{H}_{3}=156.9, \mathrm{p}=0.0001\right)$ (Table I). A post hoc multiple comparison of means did not find significant differences between juveniles in position 2 and calves in position $2(\mathrm{p}=0.2)$.

The mean group size was $28.4 \pm 31.7$ for transverse position 1 and $20.2 \pm 25.5$ for transverse position 2 . The group size showed significant differences relative to the duration of transverse care (Mann-Whitney test, $\mathrm{U}=702.0, \mathrm{~N}_{\text {position } 1}=2,904$, $\mathrm{N}_{\text {position 2 }}=616, \mathrm{p}=0.0000001$ ) (Table I).

The length of time that adults located themselves in transverse position 1 and in transverse position 2 differed significantly according to the behavioral state of the group,(Kruskal-Wallis test, $\mathrm{N}=2,633, \mathrm{H}_{3}=245.1, \mathrm{p}=0.0001$ ) (Table I). A post hoc multiple comparison of means did not find a significant difference between offspring traveling in position 2 and offspring feeding in position $2(\mathrm{p}=0.5)$.

\section{Longitudinal vs. transverse care}

Using the four previously defined sub-categories, we observed adults positioning themselves both ahead of the offspring and between the offspring and the boat (TC) for a total of 153,384 seconds (mean $60 \pm 67$ s, range $7-565$ s) (79.3\%). Adults were observed locating themselves between the boat and the offspring but not ahead of the offspring (TTC) for a total of 19,596 seconds (mean $53 \pm 63 \mathrm{~s}$, range 15-361 s) (10.1\%); for a total of 15,504 seconds (mean $38 \pm 31 \mathrm{~s}$, range $12-252 \mathrm{~s})(8.0 \%)$, adults were observed locating themselves ahead of the offspring but not between the boat and the offspring (TLC); and for a total of 5,010 seconds (mean $24 \pm 15$ s, range: $3-134$ s) (2.6\%), adults were not observed ahead of the offspring or between the offspring and the boat (AC).

\section{DISCUSSION}

\section{Offspring care}

The shallow and protected waters of the western part of Ilha Grande Bay offer abundant prey (MATSUURA 1978) and may provide an ideal region to raise offspring. The combination of these features can represent a possible explanation for the high concentration of groups containing offspring within Ilha Grande Bay, the highest concentration ever reported within the geographical distribution of the Guiana dolphin (TARDIN et al. 2011). Other populations of this species throughout its distribution have been found to include large numbers of groups containing calves. In the Paranaguá estuarine complex (Paraná State), SANTOS et al. (2010) reported that $86.4 \%$ of all observed groups of Guiana dolphins contained offspring. In Sepetiba Bay, a region adjacent to Ilha Grande Bay where large aggregations of individuals have been observed, NerY et al. (2010) reported that $80.3 \%$ of all groups observed contained offspring.

Our data indicate that the degree to which offspring receive care is high in this population. Previous work with a closely related species, the common bottlenose dolphin, reported that offspring show a limited pulmonary capacity (NoREN et al. 2002), a low concentration of oxygen in the blood (Noren et al. 2002) and small muscle mass (DeArolf et al. 2000) and that for these reasons, parental care is needed to increase offspring fitness.

By positioning themselves ahead of offspring, adults may reduce the thrust required by offspring to swim by almost $60 \%$ (Weirs 2004) because the offspring benefit from the wave pressure created by the large body of the adult. This positional arrangement also reduces the fluke stroke amplitude by up to $24 \%$, as shown by captive studies of T. truncatus (Noren \& EDWARDS 2011). In this position, offspring may also have easy access to the adult's mammary glands (MANN \& SMUTs 1999), facilitating nursing. Moreover, the location of the offspring behind the adults enables the offspring to observe behaviors that are essential to their survival, especially feeding behavior. In this way, they can learn how to capture prey and can learn about the locations where concentrations of prey occur. These observations indicate a potential opportunity for social learning (BENDER et al. 2008).

Studies of different species of cetaceans - e.g., E. glacialis (Hamilton \& Cooper 2010), T. aduncus (Mann \& SMUTs 1999) and M. novaeangliae (SZABO \& DufFus 2008) - have reported that behavior in which (the adults locate themselves ahead of the offspring is a common strategy, suggesting that the benefits received by the offspring are high enough to be maintained. However, the costs imposed on adults as a result of this position may directly affect the fitness of the adults. Noren (2007), 
working with captive $T$. truncatus, reported that the costs of this behavior for the adults are similar to those associated with the infant carrying behavior displayed by primates. The speed of adults traveling ahead of their offspring was found to be $76 \%$ less than the speed of adults traveling without offspring (Noren 2007). Moreover, the distance to which dolphins could reach when hitting their flukes in the water was decreased by 13\% (Noren 2007). Despite the lack of data for Guiana dolphins, we believe that adults face energetic costs similar to those reported for T. truncatus. Despite all of these costs, longitudinal care, i.e. adults locating themselves ahead of the offspring, is clearly evident in $S$. guianensis.

Our investigation of the influence of group size on longitudinal care showed that care was more intense if there were more individuals in a group. One hypothesis that we may derive from this outcome is that mothers maintaining offspring in close proximity can directly observe offspring behavior by visually or acoustically monitoring the offspring. This capability appears to be of great importance in large groups in which several individuals may be difficult to detect through direct observation due to the dilution effect. The ability to monitor offspring is especially important during travel to the outer part of the bay, as indicated by evidence of shark bites on a freeranging $S$. guianensis during our sampling cruises (unpublished data)When traveling in close proximity, offspring may derive greater benefits from social learning. In fact, information about social learning is useful for understanding the behavioral dynamics of certain mammalian populations and may also be useful for conservation purposes (Custance et al. 2002).

Our data show that longitudinal care is more intense during traveling than during feeding. During traveling, when the dolphins swam in fixed directions for a prolonged period, a greater amount of time spent in longitudinal care appears to be more beneficial because it allows the offspring to accompany the entire group. This opportunity can be important because the underdeveloped physiology of the offspring does not allow them to travel unaided for long distances (NOREN 2007). They gain hydrodynamic benefits by locating themselves behind adults (WeIHs 2004). During feeding bouts observed in Ilha Grande Bay, individuals performed movements of short distance and duration to capture prey (TARDIN et al. 2011). The benefits to be gained from care during feeding appear to be less important than the benefits to be gained while traveling. During feeding, it is more important that the offspring accompany the group to learn the coordinated feeding tactics used to capture prey. This function is facilitated by the ability to behave more freely within the group. TARDIN et al. (2011), working with the same species in the same study area, reported that offspring were present in $95 \%$ of all groups engaged in coordinated feeding behavior.

We observed that adults providing transverse care located themselves between the boat and the offspring more often than would be the case according to a random scenario. This result may suggest that the benefits provided to the offspring may be high enough to favor the continued performance of this behavior by adults. Transverse care allows offspring to benefit from the dilution effect. The rate of collisions with boats is reduced because another individual is positioned between the potential source of injury (the boat) and the offspring (TURNER \& Pitcher 1986).

These advantages suggest that parental care yields an increase in offspring fitness, reflecting the offspring's enhanced probability of survival. Indeed, a high rate of mortality is observed in cetaceans at this age (WHITEHEAD \& MANN 2000), and collisions with boats may be fatal to the offspring, especially in view of the weaker physiological state of immature animals (Noren et al. 2002). However, transverse care increases the rate of collisions between adults and boats, decreasing adult survival as a cost associated with this form of parental care. In fact, boats may be a relevant source of injury in Ilha Grande Bay, where almost $30 \%$ of injured dolphins showed marks and scars resulting from collisions with boats (Felipe Torres D'Azeredo, pers. comm.).

Our comparisons involving the sizes of the groups containing both the adult and the offspring were accompanied by the observation that transverse care was more intense in larger groups. This finding may suggest that the close transverse proximity to the adult may minimize agonistic interactions with other individuals, especially in view of the high mortality associated with this age class, as found in T. aduncus (WHITEHEAD $\&$ MANN 2000). These agonistic interactions between adults and offspring occur because the females are not receptive for mating during the lactation period. If the offspring dies, the female may become able to copulate and produce other offspring (WhiteheAd \& MANN 2000). In a study of S. guianensis conducted in Sepetiba Bay, a bay adjacent to the study area, NERY \& SIMÃo (2008) observed a case of infanticide, in which adult individuals interacted agonistically with the offspring, causing its death. Such interactions are not unique to this taxon. In mammals, infanticide is also known in langurs, Semnopithecus entellus (Dufresne, 1797) (Ren et al. 2011). If adults remain in close proximity to their offspring, locating themselves between a possible source of injury (in this case an adult male) and their offspring, the offspring obtains a benefit from this behavior through the dilution effect (Landeau \& Terborgh 1986). In this situation, the rate of attacks on the offspring is reduced because the adult positions itself to create a physical barrier that prevents males from reaching the offspring.

We found that the behavioral state of the group significantly influenced the degree of transverse care. Transverse care was more intense during traveling than during feeding. Note that traveling dolphins often swam to outer areas of the bay. The features of these areas differ from those of the protected and shallow inner waters. In the open and deep waters of the outer bay, offspring may encounter predators and, therefore, risk death. Weir et al. (2008), working with the Dusky dolphin, 
Lagenorhynchus obscurus (Gray, 1828) in New Zealand, reported that groups with calves preferred shallow waters, a possible strategy for avoiding predators. Moreover, feeding behavior involves the other adults in the group in prey capture. During feeding, the other adults are not concerned with the behavior of the mother-offspring dyad. As a result, the offspring are less in need of protection.

Our analysis of the frequencies of parental care strategies (longitudinal or transverse) indicated that Total Care, i.e., adult protection of offspring both longitudinally and transversely, was the most frequent parental care strategy and showed the highest mean duration. However, we observed a preference to protect offspring transversely if Total Care could not be provided: transverse care showed the second highest mean duration. This finding may suggest that adult protection of offspring resulting from the adult's physically locating its body between a source of injuries and the offspring appears to be relatively more important to offspring fitness than longitudinal care. These sources of injuries, such as boat collisions, predators and agonistic interactions, may pose serious threats to offspring survival.

\section{Parent-offspring conflict}

Our data indicate that parental care was more intense, both longitudinally and transversely, in calves than in juveniles. The physiological condition of the calves, with their underdeveloped locomotion and their dependence on their mothers for milk, appears to drive the decision to increase the parental care of calves. Juveniles, in contrast, are more capable of locomotion and are nutritionally independent of the adults.

Nevertheless, our data indicate that the parental care of juveniles was still intense. Our results indicate that the adults located themselves ahead of the juveniles and between the juveniles and boats more often than randomly expected. These findings suggest that the juveniles still gained benefits from adult care. However, the intensity of parental care for the juveniles was lower than the intensity of parental care for the calves. ManN \& SMuTs (1999) reported that such differences in care were in accordance with maturational processes for $T$. aduncus in Shark Bay, Australia. SzABo \& Duffus (2008), working with humpback whales in Alaska, reported that the time spent by adults with offspring during intervals of diving became less as the calves grew older.

This paper is the first study to quantify and test hypotheses about parental care in S. guianensis. The methodology represents a novel approach for assessing parental care. Replications of this research in other Guiana dolphin populations are needed to improve the knowledge of this phenomenon because, to our knowledge, this report is the first published study to investigate parental care in this species. We found that offspring were protected and that the intensity of parental care varied with group size, behavior and the developmental stage of the offspring. The data provide the first evidence of parent-offspring conflict in this species because the intensity of parental care varied with the age of the offspring. Future studies should investigate the potential of offspring to play an active role in parental care to increase the benefits that they obtain. Quantifying individual differences and the intensity of investment in parental care will help to broaden the limited knowledge of the behavior of Guiana dolphins because the parent-offspring relationship is an important element of mammalian biology. Behavioral information such as that reported here can aid the conservation of the species because it increases the knowledge of the parent-offspring relationship. This knowledge is useful for understanding social systems (SuTHERLAND 1998). The dolphins may be affected by the increase in boat traffic at Ilha Grande Bay. As a result, they may change their use of the area. The dolphins may move from neighboring islands in shallow waters (Lod 2003), used primarily as a feeding and nursery site (TARDIN et al. 2011), to other areas that may pose risks of predation to calves. Intense human activities in the area may affect the energy needed to care for calves and thus the probability of offspring survival. These issues merit consideration and must be recognized by future studies of the area.

\section{ACKNOWLEDGMENTS}

We thank Suzanne Beck for initial English revision, Dona Elza, Tico, Gilberto and students of the LBEC for their support. Rodrigo H.O. Tardin is in Programa de Pós Graduação em Ecologia e Evolução, Universidade do Estado do Rio de Janeiro and Mariana A. Espécie in Programa de Pós-Graduação em Biologia Animal, Universidade Federal Rural do Rio de Janeiro. Personnel for this study were partially supported by the Fundação de Amparo à Pesquisa do Estado do Rio de Janeiro (FAPERJ) (R.H.O. Tardin, Grant \#E-26/151.047/2007 and Grant \#E-26/100.866/2011); the Conselho Nacional de Pesquisa e Desenvolvimento (CNPq) (M.A.Espécie, Grant \#111555/20086), and the Coordenação de Aperfeiçoamento de Pessoal de Nível Superior (CAPES) (R.H.O. Tardin, and M.A.Espécie) and the Cetacean Society International.

\section{LITERATURE CITED}

Altmann, J. \& A. Samuels. 1992. Costs of maternal care: infantcarrying baboons. Behavioral Ecology and Sociobiology 29 (6): 391-398. doi: 10.1007/BF00170168

Bender, C.E.; D.L. Herzing \& D.F. BJorklund. 2008. Evidence of teaching in Atlantic spotted dolphins by mother dolphins foraging in the presence of their calves. Animal Cognition 12 (1): 43-53. doi: 10.1007/s10071-008-0169-9

CARR, T. \& R.K. Bonde. 2000. Tucuxi (Sotalia fluviatilis) occurs in Nicaragua, $800 \mathrm{~km}$ north of its previously known range. Marine Mammal Science 16 (2): 447-452.

Clutton-Brock, T. 1991. The Evolution of Parental Care. Princeton, Princeton University Press, 368p.

Custance, D.M.; A. Whiten \& T. Fredman. 2002. Social learning and primate reintroduction. International Journal of Primatology 23 (3): 479-499. doi: 0164-0291/02/0600-0479/0 
Dearolf, J.L.; W.A. Mclellan; R.M. Dillaman; D.J.R. Frierson \& D.A. PABST. 2000. Precocial development of axial locomotor muscle in bottlenose dolphins (Tursiops truncatus). Journal of Morphology 244 (3): 203-215. doi: 10.1002/(SICI)10974687(200006)244:3<203::AID-JMOR5>3.0.CO;2-V

EspécIe, M.A.; R.H.O. TARdin \& S.M. Simão. 2010. Degrees of residence of Guiana dolphins (Sotalia guianensis) in Ilha Grande Bay, south-eastern Brazil: a preliminary assessment. Journal of Marine Biological Association of the United Kingdom 90 (8): 1633-1639. doi: 10.1017/S0025315410001256

Geise, L.; N. Gomes \& R. Cerqueira. 1999. Behaviour, habitat use and population size of Sotalia fluviatilis (Gervais, 1853) (Cetacea: Delphinidae) in the Cananéia estuary region, SP, Brazil. Revista Brasileira de Biologia 59 (2): 183-194.

Hamilton, P.K. \& L.A. CoOPER. 2010. Changes in North Atlantic right whale (Eubalaena glacialis) cow-calf association times and use of the calving ground: 1993-2005. Marine Mammal Science 26 (4): 896-916. doi: 10.1111/j.1748-7692.2010.00378.x

Karczmarski, L.; V.C. Cockcroft \& A. McLachlan. 2000. Habitat use and preferences of Indo-Pacific humpback dolphins Sousa chinensis in Algoa Bay, South Africa. Marine Mammal Science 16 (1): 65-79.

Landeau, L. \& J. Terborgh. 1986. Oddity and the confusion effect in predation. Animal Behavior 34 (5): 1372-1380.

LodI, L. 2003. Seleção e uso do hábitat pelo boto-cinza, Sotalia guianensis (van Béneden, 1864) (Cetacea: Delphinidae), na Baía de Paraty, Estado do Rio de Janeiro. Bioikos 17 (1-2): 5-20.

Lodi, L. \& B. Hetzel. 1998. Grandes agregações do boto-cinza (Sotalia fluviatilis) na Baía da Ilha Grande, Rio de Janeiro. Bioikos 12 (2): 26-30.

ManN, J. \& B. SMUTs. 1999. Behavioral development in wild bottlenose dolphin newborns (Tursiops sp.). Behavior 136 (5): 529-566.

MatsuUna, Y. 1978. Exploração e avaliação de estoque de peixes pelágicos no sul do Brasil - Projeto integrado para o uso e exploração racional do ambiente marinho. São Paulo, Relatório Técnico do Instituto Oceanográfico, 46p.

Millar, J.S. 1978. Energetics of reproduction in Peromyscus leucopus: the cost of lactation. Ecology 59 (8): 1055-1061.

Monteiro-Filho, E.L.A.; M.M.S. Neto \& Domit, C. 2008. Comportamento de infantes, p. 127-138. In: E.L.A. MonteIro-FILHo \& K.D.K.A. Monteiro (Eds). Biologia, Ecologia e Conservação do Boto-Cinza. São Paulo, Páginas \& Letras Editora e Gráfica, 274p.

Murray, C.F.; E.V. Lonsdorf; L.E. Eberly \& A.E. Pusey. 2009. Reproductive energetics in free-living female chimpanzees (Pan troglodytes schweinfurthii). Behavioral Ecology 20 (6): 1211-1216. doi: 10.1093/beheco/arp114

Nery, M.F \& S.M. SimÃo. 2008. Sexual coercion and aggression towards a newborn calf of marine tucuxi dolphins (Sotalia guianensis). Marine Mammal Science 25 (2): 450-454. doi: 10.1111/j.1748-7692.2008.00275.x

NeRY, M.F.; S.M. Simão \& T.C.L. Pereira. 2010. Ecology and behavior of the estuarine dolphin, Sotalia guianensis (Cetacea, Delphinidae), in Sepetiba Bay, south-eastern Brazil. Journal of Ecology and Natural Environment 2 (9): 194-200.

Nogara, P.J. 2000. Caracterização dos ambientes marinhos da Área de Proteção Ambiental de Cairuçu - Município de Paraty - RJ. Rio de Janeiro, Technical Report, Fundação SOS Mata Atlântica, 83p.

NoRen, S.R. 2007. Infant carrying behaviour in dolphins: costly parental care in an aquatic environment. Functional Ecology 22 (2): 284-288. doi: 10.1111/j.1365-2435.2007.01354.x

NoREn, S.R. \& E.F. EDWARDs. 2011. Infant position in mother-calf dolphin pairs: formation locomotion with hydrodynamic benefits. Marine Ecology Progress Series 424: 229-236. doi: 10.3354/meps08986

Noren, S.R.; G. Lacave; R.S. Wells \& T.M. Williams. 2002. The development of blood oxygen stores in bottlenose dolphins (Tursiops truncatus): implications for diving capacity. Journal of Zoology 258 (1): 105-113. doi: 10.1017/S0952836902001243

Paredes, R.; I.L. Jones \&._D.J. Boness. 2005. Reduced parental care, compensatory behaviour and reproductive costs of thickbilled murres equipped with data loggers. Animal Behavior 69 (1): 197-208. doi: 10.1016/j.anbehav.2003.12.029

Rautenberg, M. \& E.L.A. Monteiro-Filho. 2008. Cuidado parental, p. 139-156. In: E.L.A. Monteiro-Filho \& K.D.K.A. Monteiro (Eds). Biologia, Ecologia e Conservação do Boto-Cinza. São Paulo, Páginas \& Letras Editora e Gráfica, 274p.

Ren, B.; D. Li; X. He; J. QIU \& M. Li. 2011. Female resistance to invading males increases infanticide in langurs. Plos One 6 (4): 1-4. doi: 10.1371/journal.pone.0018971

Rocha-Campos, C.C.; I.G. CÂmara \& D.J. Pretto. 2011. Plano de Ação Nacional para a Conservação dos Mamíferos Aquáticos: Pequenos Cetáceos. Brasília, Instituto Chico Mendes de Conservação da Biodiversidade, Série Espécies Ameaçadas.

Rosas, F.C.W. \& E.L.A. Monteiro-Filho. 2002. Reproduction of the estuarine dolphin (Sotalia guianensis) on the coast of Paraná, Southern Brazil. Journal of Mammalogy 83 (2): 506-515. doi: 10.1644/1545-1542(2002)083<0507:ROTEDS>2.0.CO;2

Ross, C. 2001. Park or ride? Evolution of infant carrying in primates. International Journal of Primatology 22 (5): 749 771. doi: $10.1023 / \mathrm{A}: 1012065332758$

Santos, M.C.O. \& S. Rosso. 2008. Social organization of marine tucuxi dolphins, Sotalia guianensis, in the Cananéia Estuary of Southeastern Brazil. Journal of Mammalogy 89 (2): 347 355.

SANTOS, M.C.O.; L. BARÃo-Acuña \& S. Rosso. 2001. Insights on site fidelity and calving intervals of the marine tucuxi dolphin (Sotalia fluviatilis) in south-eastern Brazil. Journal of Marine Biological Association of the United Kingdom 81 (6): 1049-1052.

Santos, M.C.O.; J.E.F. Oshima; E.S. Pacífico \& E. Silva. 2010. Group size and composition of Guiana dolphins (Sotalia guianensis) (van Bénèden, 1864) in the paranaguá estuarine complex, Brazil. Revista Brasileira de Biologia 70 (1): 111-120. 
SECCHI, E. 2010. Sotalia guianensis. In: IUCN 2012 (Ed.). IUCN Red List of Threatened Species. Version 2012.1. Available online at: http://www.iucnredlist.org [Acessed: 05.VII.2012].

SignORINI, S.R. 1980. A study of the circulation in bay of Ilha Grande and bay of Sepetiba. Part I, an assessment to the tidally and wind-driven circulation using a finite element numerical model. Boletim do Instituto Oceanográfico 29 (1): 41-55.

SimÕEs-Lopes, P.C. 1988. Ocorrência de uma população de Sotalia fluviatilis Gervais, 1853, (Cetacea: Delphinidae) no Limite Sul da sua distribuição, Santa Catarina, Brasil. Biotemas 1 (1): 57-62.

Smolker, R.A.; A.F. Richards; R.C. Connor \& J.W. Pepper. 1992. Sex differences in patterns of association among Indian Ocean bottlenose dolphins. Behavior 123 (1-2): 38-69.

SutHERLAND, W.J. 1998. The importance of behavioural studies in conservation biology. Animal Behaviour 56 (4): 801-809.

Szabo, A. \& D. Duffus. 2008. Mother-offspring association in the humpback whale, Megaptera novaeangliae: following behaviour in an aquatic mammal. Animal Behavior 75 (3): 1085-1092. DOI:10.1016/j.anbehav.2007.08.019
Tardin, R.H.O.; M.A. Espécie; M.F. Nery; F.T. D'aZeredo \& S.M. SIMÃo. 2011. Coordinated feeding tactics of the Guiana dolphin, Sotalia guianensis (Cetacea: Delphinidae), in Ilha Grande Bay, Rio de Janeiro, Brazil. Zoologia 28 (3): 291296. DOI: $10.1590 /$ S1984-46702011000300002

Trivers, R. 1974. Parent-offspring conflict. American Zoologist 14 (1): 249-264.

Turner, G.F. \& T.J. Prichter. 1986. Attack abatement: A model for group protection by combined avoidance and dilution. American Naturalist 128: 228-240.

Weir, J.S.; N.M.T. Duprey \& B WÜrsig. 2008. Dusky dolphin (Lagenorhynchus obscurus) subgroup distribution: are shallow waters a refuge for nursery groups? Canadian Journal of Zoology 86 (11): 1225-1234.

Weins, D. 2004. The hydrodynamics of dolphin drafting. Journal of Biology 3 (2): 1-23.

Whitehead, H. \& J. Mann. 2000. Female reproductive strategies of cetaceans: Life histories and calf care, p. 219-246. In: J. Mann; R.C. Connor; P. Tyack \& H. Whitehead (Eds). Cetacean Societies: Field studies of dolphins and whales. Chicago, University of Chicago Press, 448p.

Submitted: 17.IV.2012; Accepted: 20.IX.2012.

Editorial responsibility: Kleber Del Claro 